\title{
Perceived value and perceived usefulness of halal labeling: the role of religion and culture
}

\begin{abstract}
This research identifies the impact of the perceived value and perceived usefulness of a halallabeled product, culture and religion on intent to purchase and intent to patronize stores using data from 10 in-depth interviews and 303 self-administered questionnaires among British Muslims. Factor analysis and hierarchical multiple regression are used for data analysis. The results show that perceived usefulness, vertical collectivism, horizontal collectivism and religiosity predict a significant amount of variance in both types of intention. Specifically, perceived usefulness, vertical collectivism and religiosity have a positive relationship with intentions. Horizontal collectivism associates negatively with intentions. Religiosity moderates the relationships between horizontal collectivism and intentions. Perceived value associates positively only with intentions to patronize stores and religiosity moderates this link. The study is the first to emphasize the need to develop halal labeling to enhance the shopping experiences of British Muslims.
\end{abstract}

Keyword: Perceived value; Perceived usefulness; Halal label; Cultural orientation; Religiosity; British Muslims 